\title{
An overview of bankruptcy prediction models for corporate firms: A systematic literature review
}

\author{
Yin Shi iD, Xiaoni Li iD \\ Universitat Rovira i Virgili (Spain) \\ yin.shi@estudiants.urv.cat,xiaoni.li@urv.cat
}

Received August, 2018

Accepted April, 2019

\section{Abstract}

Purpose: The aim of this paper is to conduct a literature review of corporate bankruptcy prediction models, on the basis of the existing international academic literature in the corresponding area. It primarily attempts to provide a comprehensive overview of literature related to corporate bankruptcy prediction, to investigate and address the link between the different authors (co-authorship), and to address the primary models and methods that are used and studied by authors of this area in the past five decades.

Design/methodology: A systematic literature review (SLR) has been conducted, using the Scopus database for identifying core international academic papers related to the established research topic from the year 1968 to 2017.

Findings: It has been verified, firstly, that bankruptcy prediction in the corporate world is a field of growing interest, as the number of papers has increased significantly, especially after 2008 global financial crisis, which demonstrates the importance of this topic for corporate firms. Secondly, it should be mentioned that there is little co-authorship in this researching area, as researchers with great influence were barely working together during the last five decades. Thirdly, it has been identified that the two most frequently used and studied models in bankruptcy prediction area are Logistic Regression (Logit) and Neural Network. However, there are many other innovative methods as machine learning models applied in this field lately due to the emerging technology of computer science and artificial intelligence.

Originality/value: We used an approach that allows a better view of the academic contribution related to the corporate bankruptcy prediction; this serves as the link among the different elements of the concept studied, and it demonstrates the growing interest in this area.

Keywords: Bankruptcy prediction, Business failure, Financial distress, Insolvency, Default firm, SLR

Jel Codes: G10, G33, M21

\section{To cite this article:}

Shi, Y., \& Li, X. (2019). An overview of bankruptcy prediction models for corporate firms: A systematic literature review. Intangible Capital, 15(2), 114-127. https://doi.org/10.3926/ic.1354 


\section{Introduction}

Over the past 50 years, bankruptcy prediction has been a field of increasing interest to researchers all around the world. Many academic studies have been dedicated to exploring a corporate failure prediction model with the best accuracy. Since the breakthrough bankruptcy prediction model was introduced by Altman in 1968, a large body of research focuses on the prediction of corporate financial distress. In most cases, authors tend to use the ultimate failure (bankruptcy) as the dividing line when they distinguish the failed and non-failed firms.

The exact definition of financial distress is not determined yet. From the perspective of theoretical analysis, financial distress has different degrees (Bruynseels \& Willekens, 2012). Mild financial distress may be reflected as temporary cash flow difficulty, such as the concepts like insolvency, default and etc. The most serious one is called the business failure, or bankruptcy (Sun, Li, Huang \& He, 2014). Business failure leads to the discontinuity of the firm's operation, and it has a significant effect on anyone who is related to the firm (creditors, stockholders, suppliers, among others). Consequently, the establishment of reliable business failure prediction models is of importance to the current corporate firms (Zopounidis \& Doumpos, 1999).

This study has been conducted based on research primarily using the database Scopus, considering the time frame from 1968 (the year when Altman published the Z-score model) to 2017. Twelve keywords (six primary and six secondary) were used to carry out the present literature review: Bankruptcy, Failure, Default, Distress, Early-warning, Insolvency, Score, Indicator, Ratio, Model, Prediction and Forecast. The outcome was a total of 36 combinations of keywords being used in this study so as to search the literature for framing the concept of bankruptcy prediction.

The main purpose of this study is to obtain a broader idea of the bankruptcy prediction concept, throug hiden tifying, critically evaluating and integrating findings of all relevant and high-quality studies using Scopus database. Furthermore, the trend of the development of bankruptcy prediction studies and the co-authorship among the main researchers in this area should be shown as well.

Other additional objectives are as follows:

- To observe the evolution of papers published during the years 1968-2017. (It should be noted that the year 2017 in this paper refers to a review done up to 31 December 2017)

- To identify the most frequently cited papers

- To identify the main journals in relation to the studied research field.

- To show the co-authorship among the main researchers in this area.

- To identify the most frequently used and studied models and methods in this area.

Therefore, this study is structured as follows: the first section introduces and explains the field of interest: corporate bankruptcy prediction; the second section presents the literature review of bankruptcy prediction. Section three describes the methodology applied for the study and section four provides an overview on the existing international literature in this research field. The fifth section displays the results and findings of the study. The final section presents conclusions drawn from this research.

\section{The literature review of bankruptcy prediction}

\subsection{Different terms to describe business failure}

In the literature, various authors define differently the failure of business in their studies.

Dimitras, Zanakis and Zopoudinis (1996) indicates that in the past and current investigations in business failure prediction area, scholars usually do their researches by studying some particular aspects or stages of business failure process depending on their own experience or interests, without or with little reference to the theoretical 
framework. It causes that the literature of business failure is highly fragmented, as well as the ambiguity of the definition of business failure.

According to Balcaen and Ooghe (2006), the criterion of failure is chosen arbitrarily in historical studies, whether a juridical definition of failure, namely bankruptcy (Altman, Marco \& Varetto, 1994; Hillegeist, Zanakis \& Zopoudinis, 2004; Wilson \& Sharda, 1994; Fletcher \& Goss, 1993; Lee, Han \& Kwon, 1996), or a financial distress definition is used (Pan, 2012; Jones \& Hensher, 2004; Sun \& Li, 2008; Xiao, Yang, Pang \& Dang, 2012). The latter can also be described as failure-related events such as insolvency (Langford, Iyagba \& Komba, 1993; Lepetit \& Strobel, 2013; Jackson \& Wood, 2013), default (Tserng, Chen, Huang, Lei \& Tran, 2014; Peresetsky, Karminsky \& Golovan, 2011), and etc. Meanwhile, Altman and Hotchikiss (2006) also comment that there are basically four genetic terms to describe those unsuccessful business enterprises which are failure, insolvency, default and bankruptcy.

According to the economic criteria, failure is interpreted by Altman and Hotchikiss (2006) as the realized rate of return on invested capital which is dramatically and continually lower than prevailing rates on equivalent investments taking risk into consideration.

Insolvency takes place when the liabilities of a firm are greater than its assets. It makes a firm be incapable to meet its current obligations, sending a signal of a lack of liquidity (Altman \& Hotchikiss, 2006).

Default, literally occurs when a firm fails to fulfil an obligation, especially to pay a loan or appear in a low court. Using more corporate terms, default happens when the debtor violates a condition of an agreement with a creditor and can be the grounds for legal action. (Altman \& Hotchikiss, 2006)

Altman and Hotchikiss (2006) state that there are two types of bankruptcy. The first refers to the net worth position of an enterprise. The second type which is more observable refers to the firm's formal declaration in a federal district court, accompanied by a petition either to liquidate its assets or attempt a recovery program. While Ross, Westerfield and Jaffe (1999) concluded by summarizing the previous studies that there are three types of bankruptcy: legal bankruptcy, which literally means that the company goes to court for a declaration of bankruptcy; technical bankruptcy, which describes the situation that a company cannot fulfill the contract on schedule to repay principal and interest; and accounting-bankruptcy, which refers to the situation when a company is simply showing negative book net assets.

Other authors investigate early warning signals which provides forecasting of bankruptcy risk of firms (Korol \& Korodi, 2011). The word early warning was used originally in the military area, but now this concept is widely applied in some other fields such as: macroeconomics, business administration, environmental monitoring, and etc. Therefore, early warning of business failure is also an important term in the research field of bankruptcy prediction.

\subsection{Models applied by different authors}

Since Altman published one of the most well-known bankruptcy prediction models in 1968, a multitude of bankruptcy prediction models have flooded the literature (Gissel, 2007). It not only means the increasing number of papers published, but also the variety of the models used for business failure prediction. Thanks to the development of statistical techniques and information technology in recent years, more and more different predictive methods have been applied in order to establish a bankruptcy prediction model with a better accuracy.

Altman's model in 1968 is a five-factor multivariate discriminant analysis model. According to Gissel (2007), the primary methods that have been used for model development are multivariate discriminant analysis (MDA), logit analysis, probit analysis, and neural networks. Especially from the 1990's, due to the fact that scholars are becoming more interested in artificial intelligence technology, neural network has become one of the most widely used promising tools. Applying this method, studies carried out by Tam and Kiang (1992), Altman et al. (1994), Wilson and Sharda (1994), Fletcher and Goss (1993), Lee et al. (1996) have had great influence on later research related to business failure prediction. Furthermore, Pan (2012) intended to optimise General Regression 
Neural Network model applying algorithm and obtained a good convergence results which indicates the good prediction capability of the model.

At the same time, there are also other methods based on machine learning and artificial intelligence adopted by many authors in bankruptcy prediction area, such as rough set (Beynon \& Peel, 2001; Mckee, 2003; Xiao et al., 2012; Wang \& Wu, 2017), case-based reasoning (Li \& Sun, 2009; Li \& Sun, 2011), support vector machine (Lin, Yeh \& Lee, 2011; Li \& Sun, 2012; Kim, 2011; Chandra, Ravi \& Ravisankar, 2010) and so on. Rough set theory has been applied to a wide variety of financial decision analysis problems and it was created originally for dealing with the problem of apparent in discernibility between objects in a set. It has had a reported bankruptcy accuracy ranging from $76 \%$ to $88 \%$. Case-based reasoning, as an effective and easily understandable method for solving real-world problems, has become a vital methodology in the current business failure prediction area due to its simplicity, competitive performance with modern methods, and ease of pattern maintenance (Lin et al., 2011). Support vector machine, arose from the area of statistical learning theory and was applied into business failure prediction for the first time in 2005 (Shin, Lee \& Kim, 2005; Min \& Lee, 2005), and proved to be superior to the performance of artificial neural network. (Kim, 2011).

Since there is an increasing number of papers published related to business failure prediction from year 2000 and some other authors shed light on carrying out overviews or comparison of the business failure prediction models. Hillegeist et al. (2004) compare two accounting-based models, Altman's (1968) Z-score and Ohlson's (1980) O-score, with a market-based model developed by themselves based on Black-Scholes-Merton optionpricing model, showing that the latter can provide significantly more information than the former two. Balcaen and Ooghe (2006) undertake an overview of classic statistical methodologies in the recent 35 years, in order to understand their features as well as their related problems.

\section{Methodology}

Firstly, a systematic literature review (SLR) has been carried out applying bibliographic database Scopus, in order to identify the core papers which were published in English during the period of 1968-2017. The principal purpose is to "find all relevant individual studies, thereby making the available evidence more accessible to decision-makers." (CRD 2009).

The SLR methodology is an essential feature of any academic project. It helps the researchers to get more information about their research topic (Webster \& Watson, 2002) as it aims to address the problem by identifying, critically evaluating and integrating the findings of all relevant, high-quality, individual studies. The advantages of the SLR can be concluded as its providing of reliable information since it improves methodological transparency and enables future replication. With respect to the database applied, Scopus offers a wide overview of researches of the world, providing a massive abstract and citation database of scientific journals, books and conference proceedings (Elsevier, 2015).

Secondly, with the purpose of analyzing co-authorship among different articles related to bankruptcy prediction, the program NodeXL was used to facilitate the identification of the concepts and to create a network analysis that is visualized in a way so as to make it easy to observe the existing relationships among different authors (NodeXL, 2013).

\section{Identification of keywords and article sampling}

In order to answer the research questions, initial search for identifying the international academic papers related to the research topic were carried out by using 36 combinations of a total of twelve keywords (six primary and six secondary) as searching criteria. The details of the keyword combination design as shown below in Figure 1: 


\begin{tabular}{|l|}
\hline Bankruptcy \\
OR \\
Default Firm \\
OR \\
Early-warning \\
OR \\
Failure Prediction \\
OR \\
Financial Distress \\
OR \\
Insolvency \\
\hline
\end{tabular}

\begin{tabular}{|l|l|}
\cline { 2 - 2 } & Model \\
OR \\
AND & Prediction \\
OR \\
Forecast \\
OR \\
Indicator \\
OR \\
Ratio \\
OR \\
Score \\
\hline
\end{tabular}

Figure 1. Design of keywords combinations for the initial searching

After applying all considered combinations of primary and secondary keywords, the total number of the publications that had been found in Scopus database (up to December 2017) was 1259. The detailed search results are divided into six sections as shown in the Tables 1 to 6 :

\begin{tabular}{|l|l|r|}
\hline Secondary keyword & Primary keywords & Number of articles \\
\hline \multirow{4}{*}{ Model } & Bankruptcy & 169 \\
\cline { 2 - 3 } & Default firm & 10 \\
\cline { 2 - 3 } & Early-warning & 123 \\
\cline { 2 - 3 } & Failure prediction & 77 \\
\cline { 2 - 3 } & Financial distress & 85 \\
\cline { 2 - 3 } & Insolvency & 28 \\
\hline Total & & 492 \\
\hline
\end{tabular}

Table 1. Searching result using combination of keywords set number 1

\begin{tabular}{|l|l|r|}
\hline Secondary keyword & Primary keywords & Number of articles \\
\hline \multirow{4}{*}{ Prediction } & Bankruptcy & 184 \\
\cline { 2 - 3 } & Default firm & 5 \\
\cline { 2 - 3 } & Early-warning & 36 \\
\cline { 2 - 3 } & Failure prediction & 186 \\
\cline { 2 - 3 } & Financial distress & 63 \\
\cline { 2 - 3 } & Insolvency & 16 \\
\hline Total & & 490 \\
\hline
\end{tabular}

Table 2. Searching result using combination of keywords set number 2

\begin{tabular}{|l|l|r|}
\hline Secondary keyword & Primary keywords & Number of articles \\
\hline \multirow{5}{*}{ Forecast } & Bankruptcy & 7 \\
\cline { 2 - 3 } & Default firm & 0 \\
\cline { 2 - 3 } & Early-warning & 3 \\
\cline { 2 - 3 } & Failure prediction & 4 \\
\cline { 2 - 3 } & Financial distress & 2 \\
\cline { 2 - 3 } & Insolvency & 32 \\
\hline Total & & \\
\hline
\end{tabular}

Table 3. Searching result using combination of keywords set number 3

\begin{tabular}{|l|l|r|}
\hline Secondary keyword & Primary keywords & Number of articles \\
\hline \multirow{5}{*}{ Indicator } & Bankruptcy & 7 \\
\cline { 2 - 3 } & Default firm & 0 \\
\cline { 2 - 3 } & Early-warning & 59 \\
\cline { 2 - 3 } & Failure prediction & 2 \\
\cline { 2 - 3 } & Financial distress & 7 \\
\cline { 2 - 3 } & Insolvency & 2 \\
\hline Total & & 77 \\
\hline
\end{tabular}

Table 4. Searching result using combination of keywords set number 4 


\begin{tabular}{|l|l|r|}
\hline Secondary keyword & Primary keywords & Number of articles \\
\hline \multirow{4}{*}{ Ratio } & Bankruptcy & 54 \\
\cline { 2 - 3 } & Default firm & 1 \\
\cline { 2 - 3 } & Early-warning & 2 \\
\cline { 2 - 3 } & Failure prediction & 21 \\
\cline { 2 - 3 } & Financial distress & 28 \\
\cline { 2 - 3 } & Insolvency & 9 \\
\hline Total & & 115 \\
\hline
\end{tabular}

Table 5. Searching result using combination of keywords set number 5

\begin{tabular}{|l|l|r|}
\hline Secondary keyword & Primary keywords & Number of articles \\
\hline \multirow{5}{*}{ Score } & Bankruptcy & \\
\cline { 2 - 3 } & Default firm & 28 \\
\cline { 2 - 3 } & Early-warning & 1 \\
\cline { 2 - 3 } & Failure prediction & 5 \\
\cline { 2 - 3 } & Financial distress & 9 \\
\cline { 2 - 3 } & Insolvency & 8 \\
\hline Total & & 53 \\
\hline
\end{tabular}

Table 6. Searching result using combination of keywords set number 6

Among all the results searched by using every combination of keyword, there is one primary keyword "Bankruptcy" presents highest amount of publications when it is combined with the secondary keywords (See Table 7).

\begin{tabular}{|l|l|r|}
\hline Primary keyword & Secondary keywords & Number of articles \\
\hline Bankruptcy & Model & 169 \\
\cline { 2 - 3 } & Prediction & 184 \\
\cline { 2 - 3 } & Forecast & 7 \\
\cline { 2 - 3 } & Indicator & 7 \\
\cline { 2 - 3 } & Ratio & 54 \\
\cline { 2 - 3 } & Score & 28 \\
\hline Total & 449 \\
\hline Proportion of total searching results & $35.7 \%$ \\
\hline
\end{tabular}

Table 7. Searching result using combination of keywords set number 7

The sampling and selection process of papers has been carried out considering the following steps, as seen in Table 8. Firstly, duplicates were removed in order to ensure unbiased results. Secondly, the exclusion of articles was realized on the basis of reviewing the title and abstract. Studies that are related to corporate bankruptcy prediction and were published within the period between 1968 and 2017 were included in our review. Also, those studies focusing on subjects other than corporate bankruptcy predications were excluded as it would not necessarily be highly corresponded to the research topic. For instance, papers related to the prediction of weather or early-warning of the potential wildfire in the forest were not included into this review. After examining the abstracts of the rest 676 papers, those studying prediction models designed for macroeconomic aspect which are not precisely of the corporate area, were also removed. Finally, 496 papers have been included as literature for the present review.

\begin{tabular}{|l|r|r|}
\hline Concept & Eliminated & Number of considered paper for the SLR \\
\hline Total initial search results & - & 1.259 \\
\hline Removal of duplicates & 515 & 744 \\
\hline $\begin{array}{l}\text { Removal of "non-applicable" papers by each } \\
\text { combination (title) }\end{array}$ & $(68)$ & 676 \\
\hline $\begin{array}{l}\text { Removal of "non-applicable” papers by each } \\
\text { combination (abstract) }\end{array}$ & $(180)$ & 496 \\
\hline
\end{tabular}

Table 8. Sample of publications SCOPUS 
Additionally, due to the fact that the most classic study in this research topic, published by Altman in 1968 -Financial Ratios, Discriminant Analysis And The Prediction Of Corporate Bankruptcy-is not included in the list of searching results, while the used searching keywords are highly coincided with the keywords established by the author Altman, we consider the technologic limitation of that period may cause a non-digital keywords identification, which unable the automatic link between the used searching keyword and the article. Therefore, considering the importance of this article, the authors decide to add it manually into the literature.

According to the procedure followed, the final set of relevant articles consisted of 496 academic articles, which were used as the basis for the present study.

\section{Descriptive results}

This section shows the descriptive results obtained from the 496 articles from the Scopus database, for the period 1968- 2017 covered by this research.

\subsection{Evolution of published papers}

Figure 2 shows the evolution of the final selection of international academic articles $(n=496)$ that have been selected following an exhaustive SLR.

In particular, during the decade of 2008-2017, the number of publications has increased significantly, representing $83.50 \%$ of total analyzed. This total reflects the growing importance of the topic studied in recent years.

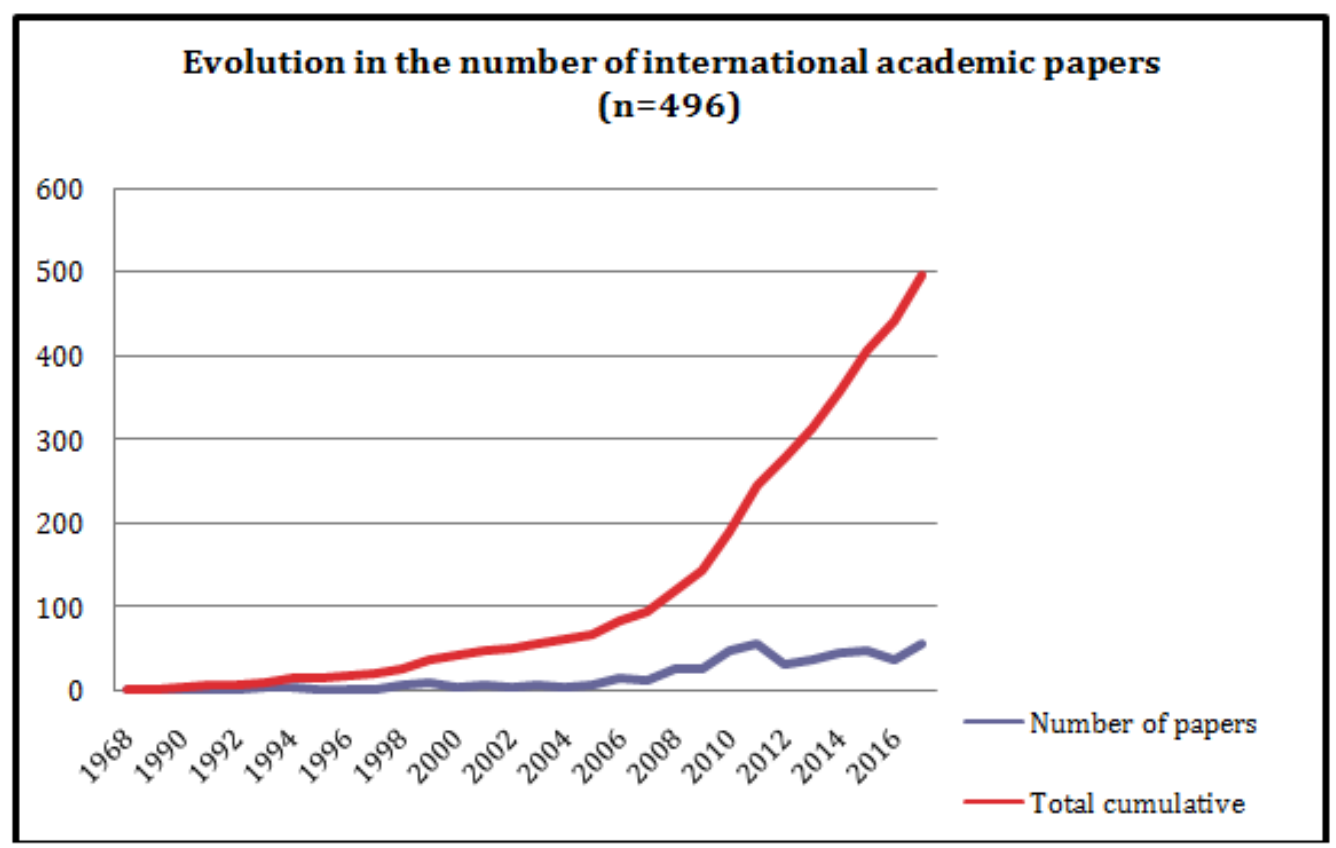

Figure 2. Evolution in the number of international academic articles during the years 1968-2017

As it also can be seen, during the years 1968-1999, there were very few articles published. It can be observed that there is a growing trend in terms of number of papers published since year 2000. Also, after the 2008 worldwide financial crisis, researchers started to explore much more this field of study achieving a dramatic increase in scientific publications.

\subsection{Most frequently-cited papers in Scopus}

Table 9 provides information on the most frequently-cited articles, considering the authors, the title, and the year of publication, as well as the total number of citations obtained after the publication. The most cited article is 
published by Altman in 1968, titled "financial ratios, discriminant analysis and the prediction of corporate bankruptcy", with 3461 citations in total. The second ranked paper is written by Tam and Kiang (1992), which obtained 595 citations.

\begin{tabular}{|c|c|c|c|c|}
\hline & Authors & Title & $\begin{array}{l}\text { Year of } \\
\text { publication }\end{array}$ & Total citations \\
\hline 1 & Altman & $\begin{array}{l}\text { Financial ratios, discriminant analysis and the } \\
\text { prediction of corporate bankruptcy }\end{array}$ & 1968 & 3461 \\
\hline 2 & Tam and Kiang & $\begin{array}{l}\text { Managerial applications of neural networks: The case } \\
\text { of bank failure predictions }\end{array}$ & 1992 & 595 \\
\hline 3 & Pan & $\begin{array}{l}\text { A new Fruit Fly Optimization Algorithm: Taking the } \\
\text { financial distress model as an example }\end{array}$ & 2012 & 364 \\
\hline 4 & Altman et al. & $\begin{array}{l}\text { Corporate distress diagnosis: Comparisons using linear } \\
\text { discriminant analysis and neural networks (the Italian } \\
\text { experience) }\end{array}$ & 1994 & 360 \\
\hline 5 & Hillegeist et al. & Assessing the probability of bankruptcy & 2004 & 348 \\
\hline 6 & Wilson and Sharda & Bankruptcy prediction using neural networks & 1994 & 332 \\
\hline 7 & Fletcher and Goss & $\begin{array}{l}\text { Forecasting with neural networks. An application using } \\
\text { bankruptcy data }\end{array}$ & 1993 & 217 \\
\hline 8 & Balcaen and Ooghe & $\begin{array}{l}35 \text { years of studies on business failure: An overview of } \\
\text { the classic statistical methodologies and their related } \\
\text { problems }\end{array}$ & 2006 & 196 \\
\hline 9 & Beynon and Peel & $\begin{array}{l}\text { Variable precision rough set theory and data } \\
\text { discretization: An application to corporate failure } \\
\text { prediction }\end{array}$ & 2001 & 189 \\
\hline 10 & Lee et al. & $\begin{array}{l}\text { Hybrid neural network models for bankruptcy } \\
\text { predictions }\end{array}$ & 1996 & 141 \\
\hline
\end{tabular}

Table 9. Most frequently cited academic articles base on the systematic literature review

As shown in the Table 9, a set of authors demonstrated the importance of bankruptcy prediction and its close connection with the corporate world. It should be mentioned that, among the first ten papers under the aforementioned criteria of ranking, six papers are based on the neural network theory (except the first one, which used multivariate discriminant analysis; the ninth one, which used rough set and the fifth and eighth ranked papers, which are overview studies).

\subsection{Most productive and cited journals}

The authors analyzed which journals are the most productive and most frequently-cited in this research field, considering the 496 obtained from the systematic literature review and their corresponding ranking.

\begin{tabular}{|l|l|r|r|r|}
\hline Ranking & Journal name & $\begin{array}{l}\text { Number of articles } \\
\text { in this study }\end{array}$ & $\begin{array}{l}\text { Number of } \\
\text { citations }\end{array}$ & $\begin{array}{l}\text { Impact } \\
\text { factor 2016 }\end{array}$ \\
\hline 1 & TheJournal of Finance & 1 & 3461 & 5,290 \\
\hline 2 & Knowledge-BasedSystem & 21 & 1030 & 4,529 \\
\hline 3 & DecisionSupportSystems & 12 & 913 & 3,222 \\
\hline 4 & Journal of Banking and Finance & 9 & 780 & 1,776 \\
\hline 5 & Management Science & 2 & 628 & 2,822 \\
\hline 6 & Omega & 7 & 454 & 4,029 \\
\hline 7 & Review of Accounting Studies & 5 & 481 & 1,756 \\
\hline 8 & Information and Management & 2 & 240 & 3,317 \\
\hline 9 & British Accounting Review & 3 & 234 & 2,135 \\
\hline 10 & Journal of International Money and Finance & 2 & 133 & 1,853 \\
\hline Total number of articles published by top 10 ranking journals & 64 & & \\
\hline
\end{tabular}

Table 10. The most productive and most frequently cited journals according to the systematic literature review

Table 10 shows the top ten most productive journals of all the journals that have been collected in this literature review. These10 journals in the ranking published 12.9\% (64 of 496 papers) of the total set of papers included in 
this study, which means that the research topic is dispersed and distributed in a large number of different journals.

It is worth mentioning that the first ranked journal, The Journal of Finance, has the highest number of citations in this research filed mainly due to the publication of Altman (1968). While the second ranked journal is the one that published most papers (21 of total 64 papers, representing 33\% in the top 10 ranking list), with a total citation of 1030 which is much lower than the first ranked one. The authors also notice that there is a huge difference in terms of number of papers published from the top 1 ranked journal to the top 10 since the tenth ranked journal only published 2 papers with 133 citations which accounts for $3 \%$ of the total citations from the first ranked journal (3461 citations).

\subsection{Relationship among authors (co-authorship)}

In order to demonstrate collaborations among the different authors belong to the selected set of articles as part of the SLR, a co-authorship has been created with the application of NodeXL, an analysis tool specialized in interactive social network visualization. It should be mentioned that, only the authors of the first 25 most frequently-cited papers have been considered due to the huge number of papers collected in our literature (496 papers). Therefore 45 authors were considered for the analysis of co-authorship in this study.

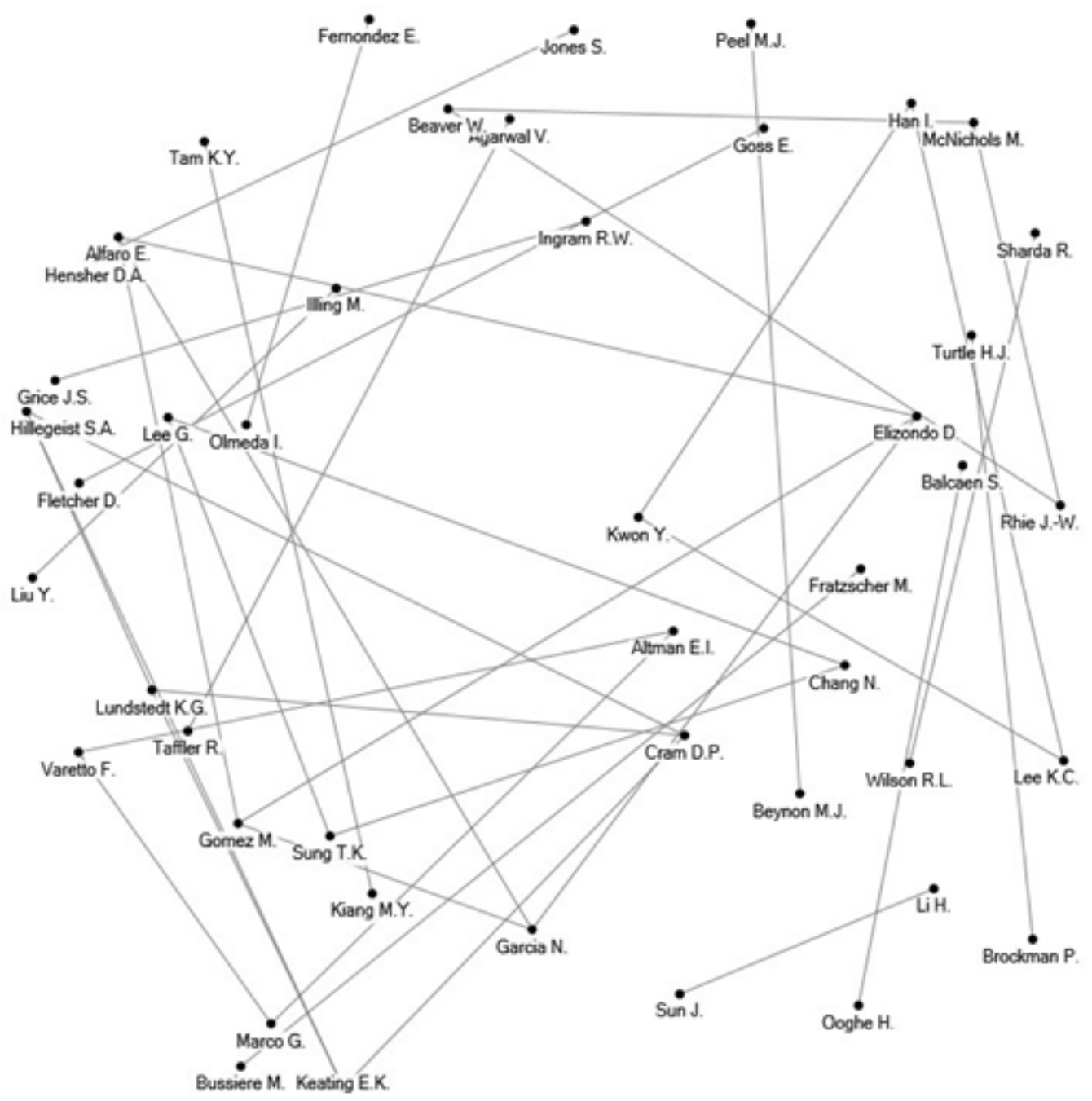

Figure 3. Co-authors hip among the authors (Created by the authors, using NodeXL) 
As shown in the map, during the evolution of the time considered in the study, the investigating activities were carried out separately, as in a group of authors there are only two or three, occasionally four researchers working together and barely with connection to other groups.

Therefore, it can be detected that there is low degree of collaborations among authors, as there is little density in the co-authorship map (with graph density 3.6\%), showing that the main researchers were not working together closely in the past years in this study.

\subsection{Most popular methods \& models studied by authors}

Reviewing the title, abstract and keyword of the sample (496 papers), we addressed some primary methods and models that have been applied or studied since 1968. It is observed that, not all 496 papers reflected the model type that are used or studied in their title, abstract or keywords. In this case, there are 175 papers that haven not mentioned and applied any models upon the aforementioned criteria. Thus, the information that we have obtained will be based on the rest of the sample: 321 papers. It is also worth mentioning, as the fact of that one paper can use or analyze more than one model, the sum of all the result doesn't have to be 321 papers exactly.

Among all the primary models and methods, it can be divided generally into two groups: statistical and machine learning. We conduct a ranking (see Table 11 and 12) according to each group, which is shown as below:

\begin{tabular}{|c|l|r|}
\hline \multicolumn{2}{|c|}{ CLASSICAL STATISTICAL MODELS } \\
\hline Ranking & Method \& model name & Number of papers \\
\hline 1 & Logistic regression (Logit) & 123 \\
\hline 2 & Discriminant analysis & 52 \\
\hline 3 & Multivariate Discriminant analysis \& Z-score & 33 \\
\hline 4 & Hazard & 19 \\
\hline 5 & Logit and probit & 7 \\
\hline 6 & Probit & 6 \\
\hline
\end{tabular}

Table 11. Ranking of classical statistical models

\begin{tabular}{|c|l|r|}
\hline \multicolumn{2}{|c|}{ MACHINE LEARNING AND ARTIFICIAL INTELLIGENCE MODELS } \\
\hline Ranking & Method \& model name & Number of papers \\
\hline 1 & Neural Network & 56 \\
\hline 2 & Support vector machine & 32 \\
\hline 3 & Decision tree & 21 \\
\hline 4 & Genetic algorithm & 20 \\
\hline 5 & Fuzzy & 17 \\
\hline 6 & Rough set & 13 \\
\hline 7 & Data mining & 11 \\
\hline
\end{tabular}

Table 12. Ranking of machine learning and artificial intelligence models

As it can be seen in the Table 11 and Table 12, the most frequently used and studied model in the corporate bankruptcy prediction area is the classical statistical model: Logistic Regression, or also known as logit model, that 123 out of 321 papers are related to this model, representing $38.3 \%$ of the total sample. The second most frequently applied model is the artificial intelligence model: Neural Network, with 56 papers applied and representing $17.5 \%$ of total sample. Discriminant analysis model ranked as the third with 52 papers. The fourth and fifth ones are MDA \& Z-score (33 papers) and Support Vector Machine (32 papers). Among the first five primary models in this area, three of them are statistical and two of them are of artificial intelligence \&machine learning area, pointing out that the latter has just become more popular, thanks to the emerging technologies and development of computer science and artificial intelligence in the recent years.

We have also detected some other newly applied machine learning models which appeared after year 2007 listed as below in Table 13: 


\begin{tabular}{|c|l|r|}
\hline \multicolumn{2}{|c|}{ OTHER MACHINE LEARNING MODELS } \\
\hline Ranking & Method \& model name & Number of papers \\
\hline 1 & Adaboost & 7 \\
\hline 2 & Case-based reasoning & 6 \\
\hline 3 & Particle swarm optimization & 5 \\
\hline 4 & K-nearest neighbor & 5 \\
\hline 5 & Random forest & 5 \\
\hline 6 & Naïve Bayes classifier & 3 \\
\hline
\end{tabular}

Table 13. Ranking of other machine learning models

Although those newly emerged machine learning models are not applied very frequently at the moment, we can still detect the trend of the increasing interest on innovative models, due to the fact that big data application is becoming more and more essential in the 21 th century.

\section{Discussion and conclusions}

The first conclusion that we can address is that the bankruptcy prediction research topic is one of growing interest, especially after 2008 global financial crisis. Due to the fact that there is no precise definition of business failure, the establishment of keywords for searching the related core papers has been carried out by considering maximally the related descriptive words, such as default, insolvency, bankruptcy, etc.

After the preliminary search using Scopus database, during the period of 1968-2017 the most frequently cited article was published by Altman in 1968, with a total number of 3461 citations which keeps the highest record of citations compared to other authors. Among the ten most frequently cited papers, six of them applied neural networks as their primary theory for research. The most productive journal is Knowledge-based System due to the highest number of articles published $(\mathrm{n}=21)$ in this research area, while the journal with most citations is The Journal of Finance, mainly due to the publication of Altman's work in 1968 that achieved a great number of citations.

Through a network analysis using NodeXL, it is allowed to obtain a co-authorship map of the different authors that had been shown as result of the SLR. It was revealed that the collaboration among the main authors is weak, as they tend to work alone or in small groups and with little connection to other authors or groups when publishing studies.

We also analyzed the model and method that are applied and studied primarily in this area. The Logistic Regression (Logit) and Neural Network are the two most representative models of statistical models and artificial intelligence \& machine learning models adopted in this field of research.

Finally, the possible lines of future research are as follows:

- Further compare different models applied in the past bankruptcy prediction studies and the accuracy rate so as to draw conclusions correspondingly.

- Apply some bankruptcy prediction models to sectorial studies with empirical data so as to verify the viability of modelling.

\section{Declaration of Conflicting Interests}

The authors declared no potential conflicts of interest with respect to the research, authorship, and/or publication of this article.

\section{Funding}

The authors received no financial support for the research, authorship, and/or publication of this article. 


\section{References}

Altman, E. (1968). Financial ratios, discriminant analysis and the prediction of corporate bankruptcy. The Journal of Finance, 23(4), 589-609. http://doi.org/10.1111/j.1540-6261.1968.tb00843.x

Altman, E., \& Hotchkiss, E. (2006). Corporate financial distress and bankruptcy. Hoboken, N.J.: Wiley. https://doi.org/10.1002/9781118267806

Altman, E., Marco, G., \& Varetto, F. (1994). Corporate distress diagnosis: Comparisons using linear discriminant analysis and neural networks (the Italian experience). Journal of Banking \& Finance, 18(3), 505-529.

https://doi.org/10.1016/0378-4266(94)90007-8

Balcaen, S., \& Ooghe, H. (2006). 35 years of studies on business failure: An overview of the classic statistical methodologies and their related problems. The British Accounting Review, 38(1), 63-93.

https://doi.org/10.1016/j.bar.2005.09.001

Beynon, M., \& Peel, M. (2001). Variable precision rough set theory and data discretization: An application to corporate failure prediction. Omega, 29(6), 561-576. https://doi.org/10.1016/S0305-0483(01)00045-7

Bruynseels, L., \& Willekens, M. (2012). The effect of strategic and operating turn around initiatives on audit reporting for distressed companies. Accounting, Organizations and Society, 27(4), 223-241.

https://doi.org/10.1016/j.aos.2012.03.001

Chandra, D., Ravi, V., \& Ravisankar, P. (2010). Support vector machine and wave let neural network hybrid: Application to bankruptcy prediction in banks. International Journal of Data Mining, Modelling and Management, 2(1), 1. https://doi.org/10.1504/IJDMMM.2010.031019

CRD. Centre for Reviews and Dissemination. (2009). Systematic Reviews: CRD 'sguidance for undertaking reviens in bealthcare. Published by CRD, University of York.

Dimitras, A., Zanakis, F., \& Zopoudinis, C. (1996). A survey of business failure with an emphasis on failure prediction methods and industrial applications. European Journal of Operational Research, 90, 487-513. https://doi.org/10.1016/0377-2217(95)00070-4

Elsevier (2015). Retrieved from: www.elsevier.com (Accessed 20 March 2018).

Fletcher, D., \& Goss, E. (1993). Forecasting with neural networks. Information \& Management, 24(3), 159-167. https://doi.org/10.1016/0378-7206(93)90064-Z

Gissel, J. (2007). A Review of Bankruptcy Prediction Studies:1930-Present, Gissel, Don Giacomino, Michael D. Akers. Journal of Financial Education, 33(Winter 2007), 1-42. The author of this document, Jodi L. Gissel, published under th ename Jodi L. Bellovary at the time of publication.

Hillegeist, S., Keating, E., Cram, D., \& Lundstedt, K. (2004). Assessing the Probability of Bankruptcy. Review of Accounting Studies, 9(1), 5-34. https://doi.org/10.1023/B:RAST.0000013627.90884.b7

Jackson, R. \& Wood, A. (2013). The performance of insolvency prediction and credit risk models in the UK: A comparative study. The British Accounting Review, 45(3), 183-202. https://doi.org/10.1016/j.bar.2013.06.009

Jones, S., \& Hensher, D. (2004). Predicting Firm Financial Distress: A Mixed Logit Model. The Accounting Review, 79(4), 1011-1038. https://doi.org/10.2308/accr.2004.79.4.1011

Kim, S. (2011). Prediction of hotel bankruptcy using support vector machine, artificial neural network, logistic regression, and multivariate discriminant analysis. The Service Industries Journal, 31(3), 441-468.

https://doi.org/10.1080/02642060802712848

Korol, T., \& Korodi, A. (2011). An evaluation of effectiveness of fuzzy logic model in predicting the business bankruptcy. Romanian Journal of Economic Forecasting, 14(3), 92-107.

Langford, D., Iyagba, R., \& Komba, D. (1993). Prediction of solvency in construction companies. Construction Management and Economics, 11(5), 317-325. https://doi.org/10.1080/01446199300000036 
Lee, K., Han, I., \& Kwon, Y. (1996). Hybrid neural network models for bankruptcy predictions. Decision Support Systems, 18(1), 63-72. https://doi.org/10.1016/0167-9236(96)00018-8

Lepetit, L., \& Strobel, F. (2013). Bank insolvency risk and time-varying Z-score measures. Journal of International Financial Markets, Institutions and Money, 25, 73-87. https://doi.org/10.1016/j.intfin.2013.01.004

Li, H., \& Sun, J. (2009). Forecasting business failure in China using hybrid case-based reasoning. Journal of Forecasting, p.n/a-n/a. https://doi.org/10.1002/for.1149

Li, H., \& Sun, J. (2011). Predicting Business Failure Using an RSF-based Case-Based Reasoning Ensemble Forecasting Method. Journal of Forecasting, 32(2), 180-192. https://doi.org/10.1002/for.1265

Li, H., \& Sun, J. (2012). Forecasting business failure: The use of nearest-neighbour support vectors and correcting imbalanced samples - Evidence from the Chinese hotel industry. Tourism Management, 33(3), 622-634. https://doi.org/10.1016/j.tourman.2011.07.004

Lin, F., Yeh, C., \& Lee, M. (2011). The use of hybrid manifold learning and support vector machines in the prediction of business failure. Knowledge-Based Systems, 24(1), 95-101.

https://doi.org/10.1016/j.knosys.2010.07.009

McKee, T. (2003). Rough sets bankruptcy prediction models versus auditor signalling rates. Journal of Forecasting, 22(8), 569-586. https://doi.org/10.1002/for.875

Min, J., \& Lee, Y. (2005). Bankruptcy prediction using support vector machine with optimal choice of kernel function parameters. Expert Systems with Applications, 28, 603-614. https://doi.org/10.1016/j.eswa.2004.12.008

NodeXL (2013).Retrieved from: www.nodexl.codeplex.com (Accessed 10 March 2018).

Ohlson, J. (1980). Financial Ratios and the Probabilistic Prediction of Bankruptcy. Journal of Accounting Research, 19, 109-131. https://doi.org/10.2307/2490395

Pan, W. (2012). A new Fruit Fly Optimization Algorithm: Taking the financial distress model as an example. Knowledge-Based Systems, 26, 69-74. https://doi.org/10.1016/j.knosys.2011.07.001

Peresetsky, A., Karminsky, A., \& Golovan, S. (2011). Probability of default models of Russian banks. Economic Change and Restructuring, 44(4), 297-334. https://doi.org/10.1007/s10644-011-9103-2

Ross, S., Westerfield, R., \& Jaffe, J. (1999). Corporate finance (second ed.). Homewood IL: Irwin.

Shin, K., Lee, T., \& Kim, H. (2005). An application of support vector machines in bankruptcy prediction model. Expert Systems with Applications, 28, 127-135. https://doi.org/10.1016/j.eswa.2004.08.009

Sun, J., \& Li, H. (2008). Data mining method for listed companies' financial distress prediction. Knowledge-Based Systems, 21(1), 1-5. https://doi.org/10.1016/j.knosys.2006.11.003

Sun, J., Li, H., Huang, Q., \& He, K. (2014). Predicting financial distress and corporate failure: A review from the state-of-the-art definitions, modeling, sampling, and featuring approaches. Knowledge-Based Systems, 57, 41-56. https://doi.org/10.1016/j.knosys.2013.12.006

Tam, K., \& Kiang, M. (1992). Managerial Applications of Neural Networks: The Case of Bank Failure Predictions. Management Science, 38(7), 926-947. https://doi.org/10.1287/mnsc.38.7.926

Tserng, H., Chen, P., Huang, W., Lei, M., \& Tran, Q. (2014). Prediction of default probability for construction firms using the logit model. Journal of Civil Engineering and Management, 20(2), 247-255.

https://doi.org/10.3846/13923730.2013.801886

Wang, L., \& Wu, C. (2017). Business failure prediction based on two-stage selective ensemble with manifold learning algorithm and kernel-based fuzzy self-organizing map. Knowledge-Based Systems, 121, 99-110. https://doi.org/10.1016/j.knosys.2017.01.016

Webster, J., \& Watson, R. (2002). Analyzing the past to prepare for the future: Writing a literature review. MIS Quarterly, 26(2), 13-23. 
Wilson, R., \& Sharda, R. (1994). Bankruptcy prediction using neural networks. Decision Support Systems, 11(5), 545-557. https://doi.org/10.1016/0167-9236(94)90024-8

Xiao, Z., Yang, X., Pang, Y., \& Dang, X. (2012). The prediction for listed companies' financial distress by using multiple prediction methods with rough set and Dempster-Shafer evidence theory. Knowledge-Based Systems, 26, 196-206. https://doi.org/10.1016/j.knosys.2011.08.001

Zopounidis, C., \& Doumpos, M. (1999). Business failure prediction using the UTADIS multicriteria analysis method. Journal of the Operational Research Society, 50(11), 1138-1148.

https://doi.org/10.1057/palgrave.jors.2600818

Intangible Capital, 2019 (www.intangiblecapital.org)

\section{(c) (i) $\$$}

Article's contents are provided on an Attribution-Non Commercial 4.0 Creative commons International License. Readers are allowed to copy, distribute and communicate article's contents, provided the author's and Intangible Capital's names are included. It must not be used for commercial purposes. To see the complete license contents, please visit https://creativecommons.org/licenses/by-nc/4.0/. 